\title{
Parts of the Whole: Is Everything Equally Important?
}

\section{Dorothy Wallace}

Dartmouth College, dorothy.wallace@dartmouth.edu

Follow this and additional works at: https://digitalcommons.usf.edu/numeracy

Part of the Mathematics Commons, and the Science and Mathematics Education Commons

\section{Recommended Citation}

Wallace, Dorothy. "Parts of the Whole: Is Everything Equally Important?." Numeracy 2, Iss. 1 (2009): Article 7. DOI: http://dx.doi.org/10.5038/1936-4660.2.1.7 


\title{
Parts of the Whole: Is Everything Equally Important?
}

\begin{abstract}
Two strategies are proposed for sorting out priorities and goals in education. At the college level the column argues that goals, and therefore requirements, should be set based on the desired knowledge base of the entire population rather than the individual. At the scale of a single K-12 classroom the column argues that priority be given to content requiring most instructor intervention, describing how the structure of class time and school activities would change as a result. Implementation of these strategies would lead to more efficient use of teacher's time and effort, better allocation of systemic resources, and clarity of goals at the national level.
\end{abstract}

\section{Keywords}

numeracy, quantitative literacy, quantitative reasoning, literacy, policy, management, teacher education, elementary education, secondary education, curriculum, post-secondary education

\section{Creative Commons License}

\section{(c) (1) (8)}

This work is licensed under a Creative Commons Attribution-Noncommercial 4.0 License 


\section{Parts Of The Whole A Column by D. Wallace}

The problem of how best to improve the numeracy of a society is a thorny one, embracing the learning process of a single student but rising in scale to include the management and alteration of an entire system of education. With the issue of quantitative literacy always in mind, this column considers various aspects of the systemic workings of education, the forces acting on classrooms, teachers and students, and mechanisms of both stasis and change.

\section{Is Everything Equally Important?}

Any attempt to set priorities in education is bound to cause a large argument, and rightly so. Historically, our priorities have come from an uneasy balance between individual and societal needs. It is worth noticing, if only for a moment, that the current outcry about the effectiveness of the educational system in this country is not coming from students. We are hearing a societal demand, and the priority of a whole society is unlikely to be a perfect mirror of the needs of a given child or even the perception of those needs by the child's parent.

Society and parents do have a few traits in common, though. Both make more and more demands on schools. Neither one is willing to tell schools which of their many demands is of highest priority. Sometimes one or the other will declare a topic to have no priority whatsoever, as when all funding for the arts was cut a few years ago at a small school in Vermont. Gutting the school budget is a common response to general dissatisfaction these days, but it conveys only that and provides no strategy to schools by which they might improve instruction or at least maintain the current level as funding fluctuates. It certainly doesn't clarify the top priorities.

Any successful attempt to steer the educational enterprise as a whole must be based on a willingness to consider the student body as a population, rather than as an aggregate of individuals, each of whom is taught separately. Even so, two rather different goals for this population emerge under analysis. Both of these goals are necessary to the well being of society and both must be met, ultimately, by the educational system. Along with these two goals come two different methodologies for meeting them, both of which need to be well integrated into the structure of requirements, curricula, and even in the classroom itself. 


\section{National and Institutional Goals}

The first goal for our population of students is to educate almost all of them to a reasonable standard. We would like almost all of our high school graduates, to pick one benchmark, to have achieved a certain level of literacy, mathematical literacy, and quantitative literacy. We would like them all (with a few inevitable exceptions) to be able to read and understand articles in the newspaper, even in the science section. To do so requires all three literacies, and perhaps more beside. From a managerial standpoint, the goal here is homogeneity. We want the knowledge of an entire population to fall within a certain range at a certain age. This outcome is necessary to the functioning of a voting citizenry in a democratic society. It is a basic need.

The second goal is more difficult to describe and harder to approach, although it has been recognized at least since the Sputnik era. A healthy economy requires businesses willing to innovate. Since the beginning of the industrial revolution, business innovation can be traced to scientific advancement. In other words, making a product cheaper, better, or making a brand new product, all rest on inventions made by scientifically minded persons, usually many years before they are exploited by business. The economy rides on a bank of scientific knowledge that is usually conceived, explored and funded years earlier, independently of the support of business, by people who are not running businesses themselves. Tomorrow's economy will run on the inventions made by (economically unproductive) scientists today.

Furthermore, many of the most recent advances are of an interdisciplinary nature. Knowledge needs to be distributed around the population for such advances to happen. It is not enough to have experts in narrow fields working in isolation. By the time a high-tech product comes into existence, the advertisers, artists, marketers and product testers will have had numerous conversations with the engineers, scientists and mathematicians until all of them understand enough about the new product to make it work commercially.

So the second goal might be framed as three related desires. First of all, the country needs enough people with specialized and very advanced knowledge to fuel tomorrow's business. In other words, are there enough mathematicians, engineers, biologists, etc.? Next, there needs to be enough knowledge dispersion to guarantee cross-fertilization of ideas. For example, to produce biology majors who have only a rudimentary grasp of statistics and calculus is to cheat the future, in which biology will ultimately be the most mathematical of the sciences. Third, there needs to be enough knowledge dispersion to improve the general state of knowledge across generations. This third desire begs for a thorough reexamination of teacher preparation, not to mention parent preparation.

Both of these goals are tough demands. Most of us are more familiar with discussions of the first goal, which are at the heart of the debate about standards and standardized testing. Few have ever attempted to answer the question: how 
many mathematicians will society need in order to guarantee an economic basis in twenty years? Yet, this is just as big of a question. For example, students who major in mathematics in this country are typically choosing not to go to graduate school but to Wall Street or e-business or other jobs after graduation. Bright students from other countries populate our graduate programs of mathematics. In and of itself, this is not a bad thing. Business does not care who invents something. But consider that the National Security Administration is the largest employer of mathematicians in the country. I doubt any of us would like to think that, in twenty years, the security of the country would rest entirely in the hands of recent immigrants. Nor would we like to think that it is in the hands of the less-talented mathematicians in this country. So, a failure to entice American students into mathematics graduate programs may have a long-term effect on the security of the nation. National security includes the security of businesses that do financial transactions electronically, namely, all of them. A successful attack on the electronic infrastructure would bring the stock market to a complete halt until repairs were made.

From a managerial point of view, the second goal is one of inhomogeneity. We need a diversity of expertise in order to grow more business and provide necessary infrastructure for it. We need unknown amounts of certain kinds of advanced expertise, particularly in science and math. We need a spread of lesser expertise around the population. The strategies for achieving this are likely to run counter to strategies for achieving the first goal, which is one that points toward a certain homogeneity.

Fortunately, these two goals do not have equal weight at all age levels of student. From kindergarten through early high school, the first goal predominates. From the time a student picks a major through graduation of college or graduate school, the second goal prevails, at least the first part of it. Between tenth grade and the third year of college, both goals strive for predominance and are valued and pursued differently in different schools.

The debate about curriculum requirements rages most vehemently with regard to the late high school-early college age bracket. The question of whether algebra is really necessary for every high school graduate falls neatly along the lines of these two goals. Often this separation is the result of a poor understanding of what algebra is and what it can do, but still one can see the tension described above in the hot fog of verbiage generated on this subject. The basic debate comes down to this: "Most people never need it and would be better served learning different kinds of math," versus "Too many students are unprepared for science courses at college". It is a clean split between the need to set and meet a reasonable standard for everyone versus the need to provide a suitable knowledge base in a population. Both of these needs are real, and both need to be met. 


\section{Priorities in the Classroom}

One might assume that at the lower grade levels, where the universal need to read, write, calculate, and be familiar with our world allows for a fairly homogeneous set of educational goals, questions of priority will have been sorted out. This is not the case, and a teacher of young students must respond to a variety of demands that put him or her at the center of a tug-of-war. Even after sorting out content goals for a given year or week or day, it is unclear how to organize the work of both teacher and student so that the best learning happens.

The proliferation of standards in various subjects for the K-12 teacher to address, although a positive step for education in general, does much to confuse the issue. There are standards in mathematics, a well-understood progression of reading levels, standards in science education, and no indication of which material is critical and which merely adds breadth. Even music educators, in self-defense lest the arts be cut everywhere, have established standards for musical education, for all K-12 students in the U.S, including both state and national standards. It is no longer acceptable to be tone-deaf after a certain age. The creation of standards in various subjects is just beginning. There is no question but that many more are to come. As we shall see in future essays in this series, standards have their uses. But it is unreasonable to expect a set of standards, no matter how well accepted, to automatically guarantee teachers and their students will live up to them. In the meantime, the more standards we have, the less clear our priorities are, unless we go to the trouble of making them explicit. That is what this column is about to try to do.

Almost everyone knows a musician or artist who is self-taught. But few of us have met someone who learned to read, write or do arithmetic without adult guidance. One possible first step in setting priorities is to ask what important things it is impossible to learn on one's own. Reading, writing and arithmetic certainly come out on top here. There are other ones too; for example Newton's laws in physics are pretty hard to figure out without guidance. Reading music requires instruction at the start. How important it is might be debatable, but it certainly is a compelling example of an abstract system. It may turn out to be very useful from a developmental standpoint. There are many more important things that require direct instruction, at least for most people. This essay will not attempt to categorize them, but merely to state firmly that this would be a good basis for sorting priorities in the schools. What follows is a discussion of what education would look like if our priorities were set in this way.

Here we digress a moment to ask what a priority really is. Let us look at the question from the manager's standpoint. How shall the teacher deploy his or her energies? How shall class time and monetary resources be spent? What sorts of professional development should the district pay for? What should granting agencies be funding? To say that five things are top priorities doesn't mean that nothing else should happen during the day. It is not an ethical stance or any sort 
of statement about the value of a particular body of knowledge to the individual or society. It just means that the energy and planning, of the teacher and the whole system in which he or she works, should be weighted toward those things that students cannot possibly learn by themselves.

One useful aspect of setting priorities in this way is that they scale up or down to fit an entire system or a single lesson. It means that the first-priority topics are given the best times of day, when students are most alert. It means that the right amount of time is allotted for them, and more of the student's work is done under direct supervision of the teacher. Most importantly, it means no interruptions while working, not even to announce a school assembly or take lunch orders.

Second priority should be given to things that are critical for society or for child development but which children can largely manage by themselves, if they have opportunity, motivation, and a minimum of adult direction. Even before children can read, video and games open the door to a range of science and geography. Reading opens the door to learning about the world and what is in it without a necessary adult intermediate. In the process of reading about the world, the child improves reading ability itself. But, this kind of learning must be arranged. Children must be given some motivation to learn independently and asked to do so directly. It is supremely unfair to ask students to read terribly boring and poorly written material. Have you looked at your child's science or history textbook? There is no excuse for the kind of writing we often see in textbooks, in view of the excellent popular science and history books now available at all levels. Money spent on wonderful, engaging books, games and films is money well spent indeed.

Once motivation and information are available, some check needs to be made that the reading or other activity has happened. Once again we must ask what the priority is with respect to evaluation. Is mastery necessary or even desirable? Requiring mastery of a body of information might be counterproductive if a more important priority is fostering continued enthusiasm for learning. Again from a managerial standpoint, once a student stops wanting to learn new things, teaching the student becomes far more difficult. This consideration leads to another first priority in education: keeping student enthusiasm for learning high.

Thought must be given to what really fits the category of second priority. Newton's laws do not, for example, but the geology of volcanoes certainly does. Children can learn a lot about volcanoes from books and films, without direct adult intervention. Delegating some important topics to the second priority category has a few added benefits. The limited independent research asked of the student is teaching a meta-lesson, that of learning to learn. Students might be given wider latitude in their choice of topics to study, leading to an opportunity for exchange of information with each other through presentations, papers, posters, and so forth, strengthening different communication skills. 
Another example of second-priority education would be the type of mathematical activity designed to promote "quantitative literacy", a greatly desired outcome of education. Quantitative literacy is defined loosely as the ability of a child to use math that he or she is supposed to already know to solve real world problems. Recognizing and solving an old math problem in a new context is very difficult to do. Developing such ability requires a lot of experience, working problems in situations that are unlikely to occur to a student on his or her own. Careful setting up of these situations is required, although not necessarily by the teacher. A societal priority to create a database of contextual math problems at a variety of levels could save teachers enormous time, especially combined with a societal priority to teach aspiring teachers how to use them efficiently. Because the highest-quality classroom time should be devoted to first-priority subjects, it would be preferable to use such quantitative problems in the context of another second-priority subject, as a natural extension of a science or history exploration.

Note the management issue here. Devoting one-time societal resources to a second-priority problem could free teacher time to deal with first-priority items more successfully. Students should have the opportunity and mandate to work complex, applied math problems in a rich context. The teachers, however, should not be expected to spend vast quantities of time designing these learning activities or figuring out where to put them in the curriculum. In fact, the less expectation we put on teachers to design lessons of this sort individually, the more public funds spent on establishing a whole collection of them, the more of this sort of education will automatically become available. The use of commercially available laboratory experiments in high school and college courses is an example of this kind of efficiency. Thus, establishing priorities of the kind we are considering in this column makes the large-scale management issues much clearer.

Furthermore notice that in the above example, because the manager is managing a system, the devotion of resources directly to a second-priority activity (other than teacher's time and effort) may also result in payoff in terms of firstpriority learning. Blind allocation of resources according to some list is not the solution. A critical examination of the real system one hopes to influence is the answer. Still on the subject of quantitative literacy, we might ask from where the time for these new activities should come. The answer, in terms of priority: anywhere except from reading, writing, regular mathematics instruction, and other first-priority learning.

Third priority would be those things that are critical for society or child development, but those things that children can and will do almost entirely on their own. Here is an example. Health is critical, and health requires exercise. Americans are under-exercised, and the avoidance of exercise is an unhealthy habit that can be acquired early and persist throughout life. Furthermore, play is developmentally critical. Some schools have become so obsessed with students' 
performance on standardized tests that they have removed physical education from the curriculum. Some schools barely have recess anymore. By this argument exercise should not have top priority, but it should not have zero priority either. It would be a third-priority item, scheduled for the most sluggish times of the day, perfect right after lunch.

On the other hand, team soccer is completely unimportant. Team sports, requiring much adult instruction and organization, not to mention buses, afterschool programs, etc., take a lot of resources to accomplish the same amount of exercise as a good hot game of tag. So, as a lower-level priority, exercise should be treated carefully (in the managerial sense). Appropriate time must be made for it, and the necessary equipment provided for a variety of activities. Some children may have to be instructed to go play, but most will do it on their own. Once in a while a new game could be introduced, preferably by a parent or other volunteer. Fun and exercise and good manners would be the goals, as opposed to any particular proficiency. Teachers would gain this time to prepare for teaching higher-priority subjects that, by definition, require more effort on their part.

Now, before every soccer lover in the country picks up a pen to protest, let us be clear about what is not being said here. Nobody is saying that team soccer shouldn't exist, isn't fun, isn't great for the development of some kids. It is just not a societal priority. It makes no sense to spend public resources on it, especially precious teacher time, at the expense of far more important things.

Many types of art instruction fall into the third category. Children draw before they can write. Most draw willingly, given the opportunity and equipment. Whether provided as a pleasant diversion or integrated into higher-priority activities, doing art provides the opportunity to develop powers of observation, manual coordination, and a sense of aesthetics. It is a third priority only because children do it so willingly and get better by themselves, for the most part. Children need the opportunity to be artists, but not a lot of adult supervision. Managing art education so that it takes little direct energy from the teacher would be a good strategy. Time (teacher's or student's) for art and exercise should never be taken from higher-priority learning.

Is there a fourth category with anything in it besides team soccer? Is anything so natural that it requires nothing at all from the educational system? Sure. We all eat and sleep without benefit of course instruction. Most of us learn to cook passably well from books. We learn to garden from books, becoming amateur botanists in the process. There is no need to devote public resources to this kind of learning. Classes in canoeing, and the creation of French desserts should be the province of for-profit education only. Books from which one may learn these things on one's own should be in every local library. Parents are great resources for teaching these topics. Of course, many of these kinds of learning may form the motivational structure for a solid experience in reading, writing, math, or quantitative literacy. It is simply absolutely necessary that we be clear on our priorities. 


\section{The Preparation of Teachers}

These observations have a necessary consequence for teacher education. If the subject material with highest priority is precisely that which requires the most direct instruction from an adult, then expertise in giving such instruction should be the number-one priority for teacher education. Schools should go to any length necessary to make sure every teacher is secure in their understanding of how children learn reading and math, because it is in these subjects that students depend most heavily on their teachers. Schools need to make sure that their teachers are still enthusiastic about the material they teach, because distaste for learning is easily communicated to students. The broad range of topics fitting into second- and third-priority categories requires teachers who are also generalists, broadly read and widely curious.

\section{Management of the System}

In a well-managed curriculum, prime time should be set aside for first-priority learning. Managers must protect the time and energy of teachers, removing the unnecessary burden of dealing with low-priority items. These items, having an important place in the curriculum, must be managed so as not to be a detriment to high-priority work. Specifically at the K-12 level, managers have the responsibility of making sure all teachers are expert math and reading educators, and that the time allocated to learning those subjects is generous and interruptionfree. Second- and third-priority items, having an important place in the curriculum, should be managed so they do not drain the energy of teachers while keeping student enthusiasm for learning high.

For such an approach to work, the teachers and those who manage them must have a clear sense of how the priorities are set in their system and strong support for the need to allocate classroom time strategically. A collection of standards across all subjects and grade levels is not a useful tool for this approach.

On a larger scale, a well-managed educational system must have leaders who understand how that system is going to address the broader goals of education, as well as specific priorities within the curriculum. At the college level, managers can affect the distribution of knowledge in the general population by replacing the criteria of grades and test scores with admission policies based on strengths of students in specific desired content areas. It is certainly possible to identify students who intend (for example) to major in engineering before admitting them. A popular school that desired an incoming class where ten percent of students wanted to be engineers would have no trouble admitting that proportion of prospective engineers. Scholarships could be contingent on remaining in the major. Requirements within a college can be constructed to ensure an inter- 
disciplinary spread of knowledge among graduates. Many strategies are available once the priority of the institution becomes clear.

To address these goals the country must also find an answer to the hard question of how many professional artists/scientists/musicians/engineers/doctors/ mathematicians we really need to keep the economy strong. Our history of being an industrial economic power has made us complacently assume that plenty of people will naturally desire to excel in the technical subjects that drive innovation. As we move more toward a service economy we must replace this assumption with a clear intention to continue to produce scientific and industrial leadership, letting our intentions drive and steer our system of education. 